Atomic Physics

By Dr. Max Born. Authorised translation from the German edition by Dr. John Dougall. Pp. xii +352 . (London, Glasgow and Bombay: Blackie and Son, Ltd., 1935.) 17s. $6 d$. net.

IN 1933, Prof. Max Born published in German "Moderne Physik", which has given rise to the present English version by Dr. John Dougall. This book is, however, more than a mere translation, for it has been brought thoroughly up to date so as to include the discovery of new particles and their role in the constitution and disintegration of atomic nuclei. The author has included a clear account of his own views suggesting a higher limit to the possible magnitude of an electromagnetic field, somewhat as the velocity of light appears in physics as the maximum velocity of particles. In this way, Born retains Maxwell's equations and the usual relation between energy and mass, and obtains for the size of the electron $2.28 \times 10^{-13} \mathrm{~cm}$. and for the absolute field $9 \cdot 18 \times 10^{15}$ E.S.T., but these values may be modified by the effect of spin, which, as he points out, has not yet been satisfactorily dealt with as a real electromagnetic angular momentum from the point of view of his theory. Incidentally, there is on page 46 and appendix vii an ingenious and simple derivation of the Einstein formula $E=m c^{2}$.

This book gives a comprehensive review of modern atomic physics in 256 pages, while the proofs of formulæ are placed in 31 appendixes (87 pages). The author is careful to point out the limitations and defects of modern theories no less than to set forth their brilliant successes, while he attempts to erect signposts for guidance in future advances.

The relations between the two types of statistics and the symmetric and antisymmetric wave forms are stated with exceptional clearness. The necessarily elusive character of modern views is sufficiently indicated. A wave packet should be almost evanescent, and yet it is possible to hold in the hand a large pitchblende crystal and to state it has remained almost in its present form for 1,400 million years. The microscopic universe is as indeterminate as an animal in the Zoo, when you do not know in which cage it may be, and, if found, the animal dashes off to hide as soon as you try and look at it. Sometimes, however, it leaves a trail, sometimes flashes a light.

$$
\text { A. S. Eve. }
$$

\section{The Pineapple}

By Maxwell O. Johnson. Pp. xii +306 . (Honolulu : Paradise of the Pacific Press, 1935.) 5 dollars.

The pineapple industry of Hawaii has been built up within the last forty years. In 1896 a large consignment of plants of the 'Smooth Cayenne' variety was imported from Queensland and formed the foundation of the present industry. A few thousand canned fruit were produced by 1902, and by 1913 the production had risen to $2,600,000$ cases. It has now reached the enormous total of $12,000,000$ cases, or about $300,000,000$ marketable fruit per annum.

In 1916 cultivation was confined to the uplands, as plants grown on the lower lands suffered from what was known as 'pineapple yellows'. The discovery by the author that this was due to lack of available iron in the soil, and that the disease could be cured by spraying with iron sulphate, meant an immediate and rapid expansion of the area under pineapples. Other ailments from which the crop suffered have been investigated and largely controlled.

The author of this book, and other technical workers, have been mainly responsible for the maintenance and development of this industry, and there can scarcely be anyone more competent to write a study which deals so admirably with all aspects of cultivation of this crop and which describes in detail the methods adopted to control disease. The book closes with an account of the marketing of both the fresh and the preserved fruit.

This work not only deals with the pineapple in Hawaii but also summarises the experience gained in other countries, many of which have been visited by the author in his search for knowledge of the crop.

\section{Mid-Ice: the Story of the Wegener Expedition to Greenland}

By Johannes Georgi. Translation (revised and supplemented by the Author) by F. H. Lyon. Pp. xiv $+247+24$ plates. (London: Kegan Paul and Co., Ltd., 1934.) 12s. 6d. net.

THE Wegener expedition to Greenland in 1930 planned to maintain a meteorological observatory on the ice sheet in the heart of the country. The volume before us is the story of how this task was achieved. Transport from the coast, some two hundred and fifty miles away, broke down, but the work at the central station was not interrupted although the party, and at times Dr. Georgi alone, lived in a hole in the ice. They had food, but little else. Here in diary form is the frank record of life under those dreary conditions. Wegener himself lost his life on a journey to the coast; but the expedition has important results. Few of these, however, are given in this general volume, which has its interest chiefly in showing what man can endure in the cause of scientific discovery.

\section{China's Geographic Foundations: a Survey of the} Land and its Peoples

By Dr. G. B. Cressey. Pp. xvii +436 . (New York and London: McGraw-Hill Book Co., Inc., 1934.) 24s. net.

THE author knows China from end to end, and has produced a valuable book, which should be studied by every student of geography. So much that is written on China is solely political and superficial; but this study strikes down to basic physical conditions, and from position, relief, soil and climate builds up an explanation of Chinese life and activities. Problems of climate and their relation to agriculture are especially well treated. Manchuria and the outer dependencies of China are included. There are numerous clear maps, many excellent illustrations and copious bibliographies. Prof. Cressey has succeeded in writing geography without dullness, and given a survey of lasting value. 